Pediatr. Res. 14: 1151-1154 (1980)

\title{
Presentation of the Howland Award: Some Observations Introducing C. Henry Kempe, M.D. ${ }^{1}$
}

\author{
HENRY K. SILVER'2
}

Department of Pediatrics, University of Colorado School of Medicine, Denver, Colorado, USA

It is my great pleasure and honor to have this opportunity to introduce Dr. C. Henry Kempe, the recipient of the 1980 Howland Award of the American Pediatric Society, Dr. Kempe is an internationally renowed physician, humanitarian, laboratory and clinical investigator, educator, administrator, author, medical statesman, and crusader who, for more than 30 years, has influenced generations of medical students, residents, other physicians, and health professionals as well as the general public. He has been an effective worker and an extraordinary force in improving health, preventing disease, and furthering the rights and welfare of children throughout the world (Fig. 1).

Dr. Kempe was born in 1922 in Breslau, Germany, where he spent his childhood. His early teen years were overshadowed by the troubles in Germany under Hitler and in 1937 his family left Germany; he went to England under the auspices of a Quaker program while his parents went to South America. After a year in England, he was brought to the United States by a refugee organization, and a place was found for him in California (Fig. 2 ). He worked his way through the University of California at Berkeley, and in 1942, he entered the University of California School of Medicine. Because he was classified as an "enemy resident" at that time, he was under curfew restrictions which prevented his going to the library or anywhere else in the evenings. Six months later, however, his status changed; he simultaneously became an "instant" citizen and a private first class in the army when he and the rest of his class were called up for military service, but continued to attend school. He graduated from medical school in 1945 and had an internship in Pediatrics at the University of California Hospital. On completion of the 9-month internship, he had 2 years of additional army service as an Assistant Virologist at the Research and Graduate School in Washington, D.C. On discharge from the military, he continued his housestaff training as an Assistant Resident in the Department of Pediatrics at Yale University under Dr. Grover Powers and then returned to San Francisco to become Instructor and, subsequently, Assistant Professor of Pediatrics and Lecturer in Social Welfare at the University of California School of Medicine. In 1956, at the age of 34 and while still an Assistant Professor, he was asked to come to Denver to be Professor and Chairman of the Department of Pediatrics at the University of Colorado School of Medicine. He served as Chairman for 17 years until 1973 and has continued as Professor in the Departments of Pediatrics and Microbiology.

Dr. Kempe first became internationally famous for his studies and pioneer work on the prevention and treatment of smallpox. In his paper, which will be presented for him by Dr. Saul Krugman, he will recount for you some of his experiences with this disease which was then widespread and endemic in many parts of the world, and so I will not discuss them here.

' Presented at the $90^{\text {th }}$ Annual Meeting of the American Pediatric Society. San Antonio, Texas, April 30. 1980.

2 Address reprint requests to: Dr. Henry K. Silver, University of Colorado Health Sciences Center. 4200 E. Ninth Ave., Denver, CO 80262.
Dr. Kempe has made a number of other noteworthy contributions to the health and welfare of children. One, of especial importance, has been his work in the area of child abuse and neglect. Starting in 1958, his endeavors on this subject and in calling attention to what he so graphically termed "the battered child syndrome" captured the world's attention. He delineated the syndrome's findings; showed how to manage the families in which the condition occurred; pointed out how to assess, evaluate, and treat the children who suffered child abuse; and eventually developed the guidelines which can be used in predicting where child abuse may occur so that measures can be instituted which will help to prevent it.

Before Dr. Kempe's pioneering work, the importance of "battered children" had barely been suspected. Many persons, including health professionals, resisted accepting the idea that children could be severely injured and even killed by their parents and that this was a relatively common occurrence. Dr. Kempe took upon himself the uphill battle to fight this universal and horrible scourge, and it has been through his enormous and untiring efforts that the magnitude of the problem of child abuse came to be appreciated. First, he had to convince physicians, nurses, lawmen, and politicians of the extent of the problem which, up to then. had largely been ignored. Then, he had to show how to recognize the condition. He had to battle to change old reflexes and attitudes toward this problem and to show the need for a new kind of legislation to deal with it. In this regard, his recommendations regarding child abuse have been incorporated into legislation that has been adopted by almost every state in this country. Finally, he inspired many others in this country and abroad to become active in dealing with the problem. He traveled throughout the United States to bring the subject of child abuse to the attention of health professionals and to the lay public. Now there are literally thousands of child protection teams worldwide modeled after the one he started and for which he has compaigned since 1959.

Dr. Kempe has been described as the leading spokesman for a large but silent minority, the abused children of the world. For over 20 years, he has devoted himself to improving the plight of physically, emotionally, and sexually abused and neglected children and their unhappy parents. He has been the major contributor in bringing to light a problem so complicated and unpleasant that it is only now being adequately recognized by the public and members of the health professions alike. Through his efforts, the lives of thousands of children have been saved, and hundreds of thousands of others have been affected for the better. At the National Center for the Treatment and Prevention of Child Abuse and Neglect, a part of the University of Colorado Health Sciences Center in Denver, which he founded and heads, professionals in multidisciplinary fields are trained to deal with all aspects of child abuse. Studies at the Center have demonstrated the value of using trained laymen and women as counselors and therapists for involved families, the support that the parents of similarly affected families can give to each other, the role of "crisis" nurseries where 


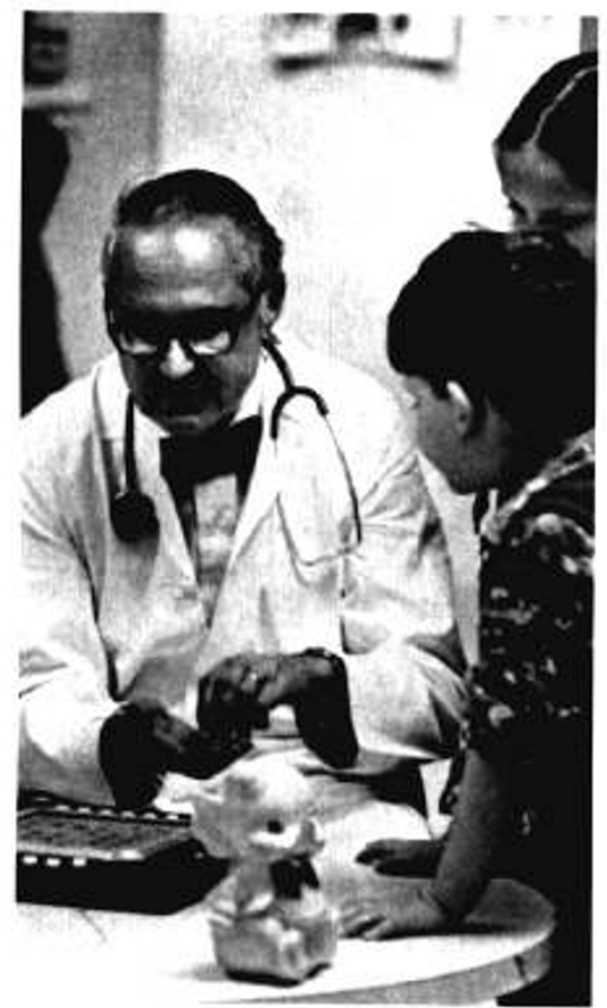

Fig. 1. Dr. Kempe with children.

parents can bring their infants for a short stay when they feel that they can no longer cope with them, the value of residential family treatment, and the significance of a number of other methods of dealing with the problem. One of those working in the area of child abuse has described Dr. Kempe's contributions to the field as "truly a living and ongoing monument to his leadership not only as a professional of outstanding quality, but as a concerned and compassionate human being who makes not only the present world better to live in, but the future for all children much more promising."

One of Dr. Kempe's greatest skills is as a teacher. His professional lifetime has been devoted to medical education - the education of the individual as well as the education of entire communities and society as a whole. He is a brilliant, stimulating, and knowledgeable teacher in many areas of medicine who presents his knowledge in a clear, concise, and articulate manner and with zest, imagination, and a marvelous sense of humor. His modesty and concern for others plus his personal striving for excellence and easy accessibility make him a gifted model for all who have known him. Even as a busy department chairman, laboratory investigator, and international figure, he devoted liberal segments of his time each week to individual and group student instruction so that his presence was felt throughout the year. Students at all levels at the Unversity of Colorado recognized his interest in them and in their education and were uniform in their praise of his efforts.

He has also taught through his more than 100 articles and approximately 40 books and chapters in books written in collaboration with many of his colleagues. These articles and books have had enormous impact on child care not only in the United States but all over the world.

Besides being a superb teacher, investigator, and outstanding in many academic fields, he is an excellent administrator. He became Chairman of the Department of Pediatrics at Colorado when it was a small department with limited faculty and very little active research. He brought the department from this level of almost complete obscurity to a position of prominence which served as a model for many others throughout the country. From his depart- ment, important information emerged in a number of areas including the care of low-birth-weight infants, standards of development of the yong child, the training of pediatric nurse practitioners, and the elucidation of a variety of metabolic disorders and infectious diseases. The Department he developed and chaired established a balanced model which ranges from the most basic laboratory investigations to studies in the psychologic and social aspects of pediatrics, community medicine, and world health.

As chairman, he was most concerned about the welfare of children and the education of a wide variety of students, including private practitioners who remain his loyal supporters. He provided for the members of his department an environment in which patient care was excellent and laboratory and clinical investigation flourished. In his department, there was a remarkably close relationship between faculty members, medical students, housestaff, and practitioners. He is accurate in his judgment of people, very humane, exceedingly honest, and able to bring out the best in people. He had faith that members of his department would be able to do things well, and he let them alone while they lived up to his expectations, which were frequently much higher than they had had for themselves. He stimulates those around him to perform at their maximum. In all that he does, his approach is both compassionate and comprehensive. In his dealings with other people, sensitivity and generosity come first, whether relating to babies, to their parents, or to distinguished peers in science. Many of Dr. Kempe's students and trainees have gone on to leadership positions in other academic institutions. Others are recognized as outstanding practitioners in the communities in which they serve.

Dr. Kempe is a superb clinician and brilliant diagnostician. He links all levels of knowledge to the improvement of the care of patients. His rounds are full of consideration for the patients and

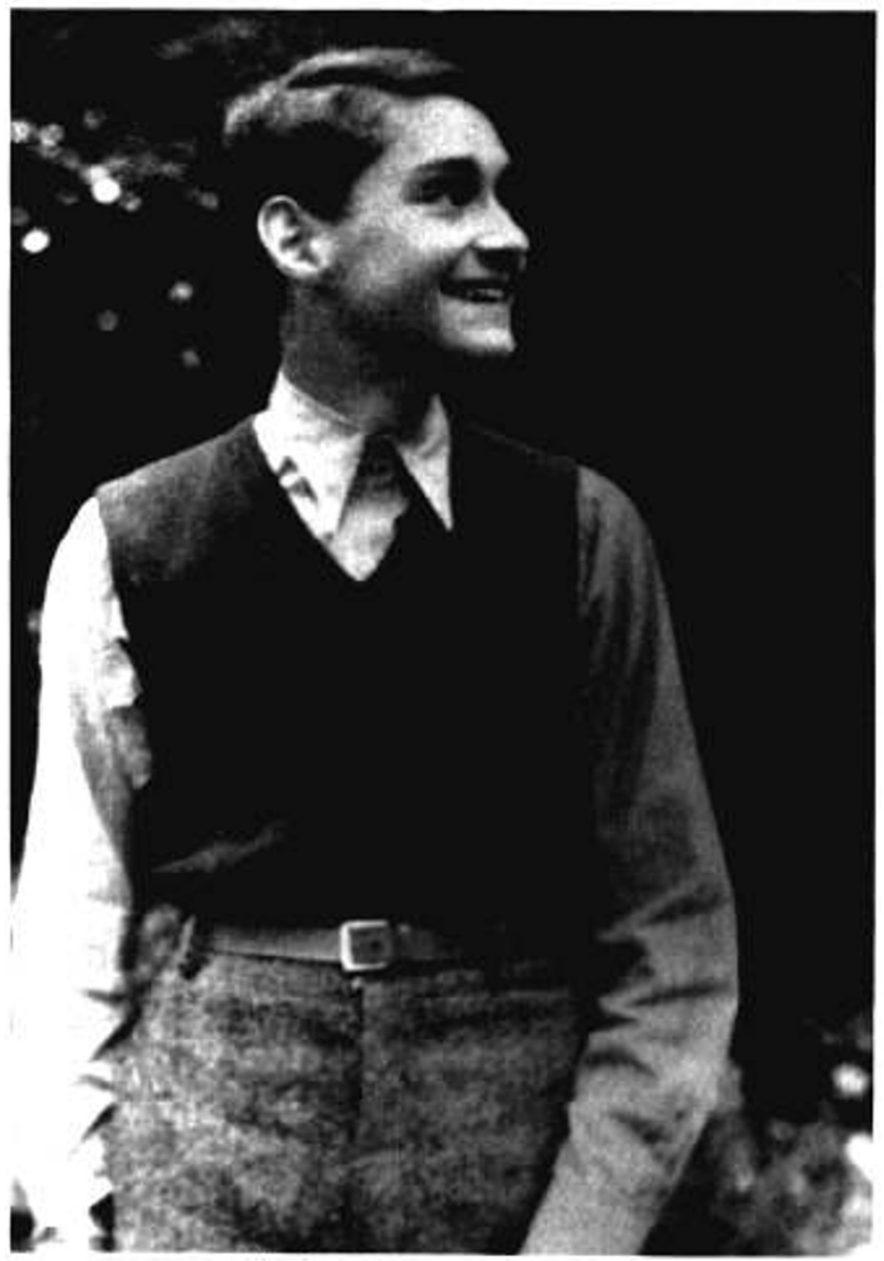

Fig. 2. C. Henry Kempe, age 16 . 
their families. Is the child getting what he or she might like to eat? Does the Spanish-speaking mother understand what is happening and why? What about her meals? Where is she sleeping?

Dr. Kempe actively sponsored the concepts of humane hospital care of children and their parents, and he was a pioneer in developing a simple in-hospital residential arrangement whereby a parent could stay and help in the care of her sick child, thus providing critically important psychologic support to her child, and, at the same time, giving support to other children in the room whose families could not stay with them. He also utilized foster grandmothers (and fathers) long before the federal government subsidized such programs.

Another of Dr. Kempe's important recent contributions was the development of a report on "The Future of Pediatric Education" by the Task Force on Pediatric Education of which he was the chairman. The Task Force was formed because of the recognition that many of the important health needs of infants, children, and adolescents were not being met as effectively and as fully as they should be. The Task Force identified these health needs and pointed out the educational strategies that are required to prepare the pediatricians of the future to meet them. Dr. Kempe's keen understanding of the pediatric educational system and his clarity of insight regarding the future of child health care made possible a concise, effective, and most useful document. Although many believed that pediatric education needed a master plan for the future, it was Henry Kempe who came forward with the right idea at the right time. Just as the Flexner Report was a seminal contribution in relation to medical education as a whole, the report on "The Future of Pediatric Education" will have a pervasive and constructive impact on pediatric education in the future.

Dr. Kempe has received a number of honors in this country and abroad. He was a Fulbright Professor of Pediatrics and Virology in Rome, a Visiting Scientist at the Pasteur Institute in Paris, and is a member of the Expert Committee on Smallpox of the World Health Organization, a Consultant to the Surgeon General of the United States, a Consultant to the British National Society for the Prevention of Cruelty to Children, President of the International Society for the Prevention of Child Abuse, and Editor-in-Chief of the International Journal, "Child Abuse \& Neglect." Two years ago, he served as President of the American Pediatric Society.

Among his many awards are the C. Mead Johnson Award for Research of the American Academy of Pediatrics, the Vincent de
Francis Award of the American Humane Society, the Jacobi Award of the American Medical Association Section on Pediatrics, the C. Anderson Aldrich Award of the American Academy of Pediatrics, the Edward W. Browning Award of the American Public Health Association, the George Armstrong Award of the Ambulatory Pediatric Association, the Nils Rosen von Rosenstein Medal of the Swedish Pediatric Society, and the Thomas Jefferson Award of the University of Colorado.

Dr. Kempe has frequently been far ahead of his contemporaries. For example, when he was president of the pediatric chairmen's organization, he proposed establishing a national health service corps as an alternative to military service to provide care for rural people and American Indians not covered by any medical system. Although this idea was not accepted at the time, the national health service corps idea eventually was adopted by Congress and was supported by medical and lay organizations throughout the country. In 1971, when he learned that radioactive tailings of uranium mines had been used in construction of homes and schools in Grand Junction, Colorado, he took his concern to Washington to try to persuade the Atomic Energy Committee to correct this threat to child health. Although the initial response was relatively negative, his efforts eventually produced results which are still making the front pages of newspapers today. He was one of the first to initiate unlimited visiting hours for hospitalized children and to permit siblings and close relatives as well as parents to visit. Visiting was arranged for the convenience of the family rather than for the staff. Many of his innovations may now seem commonplace, but when he introduced them, it took considerable effort on his part to overcome the resistance he encountered.

Dr. Kempe is married to Dr. Ruth Svibergson Kempe, a physician and child psychiatrist who has collaborated with him for over thirty years both professionally and in raising five daughters (Fig. 3). Henry met Ruth in New Haven the week he arrived there after being discharged from the army to start his assistant residency in July, 1948. She was also an assistant resident on the pediatric service and was (and is) a lovely, charming, calm, and very knowledgeable person. They had a whirlwind courtship and were engaged 4 weeks after he came to New Haven. They were married a month after that. Incidentally, this 12 -month residency at Yale along with the 9 months of internship he had had at the University of California were the only formal residency training experiences he ever had.

In San Francisco and later in Denver, the Kempe's home has

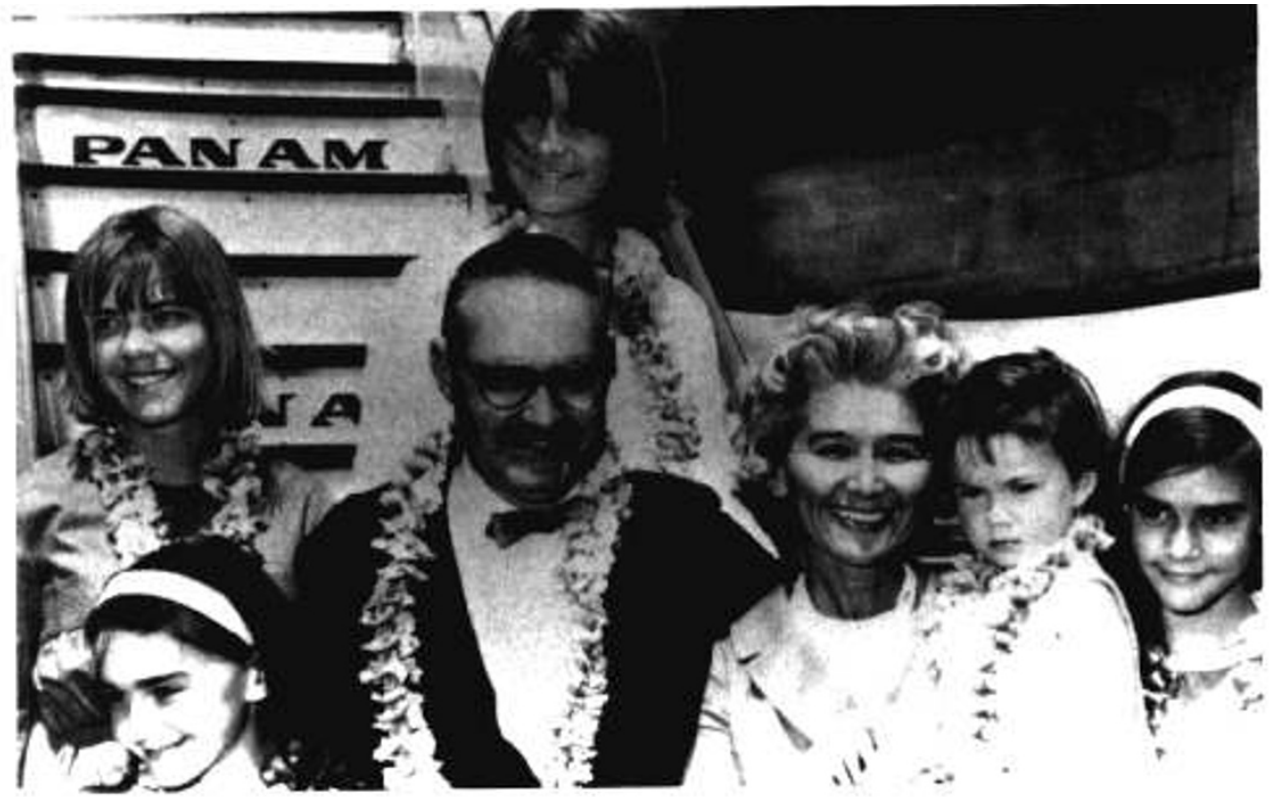

Fig. 3. The two Drs. Kempe and their five daughters, 1964 
been filled with their own family, the friends of their children, and others from all over the world. All the pediatric residents, each group of medical students as they rotated through pediatrics, friends, colleagues, and people from all walks of life have been able to experience the warmth and congeniality of being with them. Visitors from overseas, when they visit Denver, are expected as a matter of course to stay with the Kempes. The two Doctors Kempe are always delightful and considerate hosts at the innumerable dinners and other affairs at their home. To be invited to dinner has always been an event to remember-Henry at the head of the table dispensing delicious food and fine drink; lively conversation covering a host of topics; stories told as only a raconteur can tell them; the aroma of good cigars; and an all pervasive sense

Copyright (c) 1980 International Pediatric Research Foundation. Inc. $0031-3998 / 80 / 1411-1151 \$ 02.00 / 0$ of civility, friendship, and good feelings. Over the years, Ruth Kempe has truly been his helpmate and support. What they have built, they have built together, and they have made of their lives something that is fine, distinctive, and good for them as well as for others.

In closing this introduction, I would like to point out that it has been my great privilege and pleasure to be associated with Henry Kempe for over 35 years. For myself and for the many others whose lives he has touched. I thank him for all that he has done for us, for the wisdom which he shared with us, for his wise counsel, and, above all, for his friendship. It is indeed fitting that today he be awarded the Howland Award of the American Pediatric Society. 